Cite this: Phys. Chem. Chem. Phys., 2012, 14, 2921-2928

\title{
Photophysics of aminophenyl substituted pyrrolopyrrole cyanines $\uparrow$
}

\author{
Simon Wiktorowski, Georg M. Fischer, Martin J. Winterhalder, Ewald Daltrozzo \\ and Andreas Zumbusch*
}

\author{
Received 21st October 2011, Accepted 22nd December 2011 \\ DOI: $10.1039 / \mathrm{c} 2 \mathrm{cp23330d}$
}

A series of novel pyrrolopyrrole cyanines (PPCys) bearing various aminophenyl substituents at the diketopyrrolopyrrole (DPP) core are presented. Compared to their alkoxyphenyl substituted analogues, these dyes feature additional intense electronic transitions of charge-transfer character which give detailed insight into the optical properties of PPCys. The energetic mixing of the involved orbitals has pronounced effects on the absorption and fluorescence behavior. Protonation of the amino function suppresses these effects and leads to a pronounced increase in fluorescence quantum yield. The photophysics of the dyes can be rationalized by means of a simple energy scheme.

\section{Introduction}

Dyes absorbing and emitting in the near-infrared (NIR) spectral region are currently much sought after. Their possible applications come from biological as well as from material sciences. In biological labelling applications, working in the NIR spectral region provides higher penetration depths due to the lower scattering of light in tissue as well as a reduced autofluorescence background. ${ }^{1,2}$ In material scientific applications, on the other hand, NIR absorbing dyes find use in dye-sensitized solar cells (DSSCs), in the development of NIR light emitting diodes, or in optical filters for laser-protection products. ${ }^{3,4}$ This broad range of potential applications motivated research on new classes of NIR absorbing and emitting dyes. ${ }^{5-11}$ The main aim of this research is the rational design of chromophores with high photostability and specific spectral properties, e.g. high extinction coefficients or high fluorescence quantum yields.

We recently reported the synthesis and spectroscopic characterization of pyrrolopyrrole cyanines (PPCys) as a new class of near-infrared absorbing and emitting dyes. ${ }^{12-14}$ PPCys are obtained via condensation reaction of one equivalent of diketopyrrolopyrrole (DPP) 1 with two equivalents of a heteroaromatic acetonitrile (HAA) 2 by activation of the carbonyl groups of the DPP with phosphoryl chloride (Scheme 1). The resulting dyes show narrow-band absorption with high extinction coefficients in the NIR accompanied by negligible absorption in the visible spectral region.

Fachbereich Chemie, Universität Konstanz, 78457 Konstanz,

Germany.E-mail: andreas.zumbusch@uni-konstanz.de;

Fax: + 49-7531-883870; Tel: + 49-7531-882357

$\dagger$ Electronic supplementary information (ESI) available: Synthesis and characterization of aminophenyl substituted DPPs and further protonation experiments of aminophenyl substituted PPCys. See DOI: $10.1039 / \mathrm{c} 2 \mathrm{cp} 23330 \mathrm{~d}$
The hydrogen chelates (H-PPCys) 3 show no fluorescence at room temperature. High-amplitude torsional motions of the heteroaromatic end groups represent the main radiationless deactivation channel of the excited electronic state. Stiffening of the chromophore by substitution of the hydrogen atoms by $\mathrm{BF}_{2}$ or $\mathrm{BPh}_{2}$ groups leads to compounds with high fluorescence quantum yields of up to $70 \%$ in the NIR $\left(\mathrm{BF}_{2}-\mathrm{PPCys} 4\right.$ and $\mathrm{BPh}_{2}-\mathrm{PPCys} \mathbf{5}$, respectively; Scheme $1, \mathrm{X}=$ alkoxy). In this spectral region, these are the organic compounds with the highest fluorescence quantum yields known to date. The influence of the heteroaromatic end groups on the photophysical properties has been investigated in detail. It was shown that the nature of the incorporated heterocycle has a strong influence on the absorption maximum. ${ }^{13,15}$ Therefore, a fine tuning of the electronic transition energies is possible by the synthesis of asymmetric PPCys containing two different heteroaromatic end groups. ${ }^{16}$ These compounds show absorption and emission spectra lying in between those of the corresponding symmetric analogues. While structure-property relationships of this new type of chromophore have been investigated in detail, there has been no investigation concerning the nature of the substituents directly attached to the DPP core. In the aforementioned works alkoxyphenyl substituted PPCys (Scheme 1, X = alkoxy) were synthesized, which contain long alkyl chains for the improvement of solubility in common organic solvents, e.g. dichloromethane or toluene.

The aim of the work presented here is to gain a deeper insight into the photophysics of PPCys and especially the electronic interplay between the main chromophore that is oriented along the long axis of the molecule and the substituents attached to the short axis of the chromophore (Fig. 1). Therefore, we describe the synthesis and photophysical properties of alkylated and/or arylated para-aminophenyl substituted PPCys (Scheme 1, X = alkyl- and/or arylamino) as test systems. The spectroscopic properties of these dyes will 


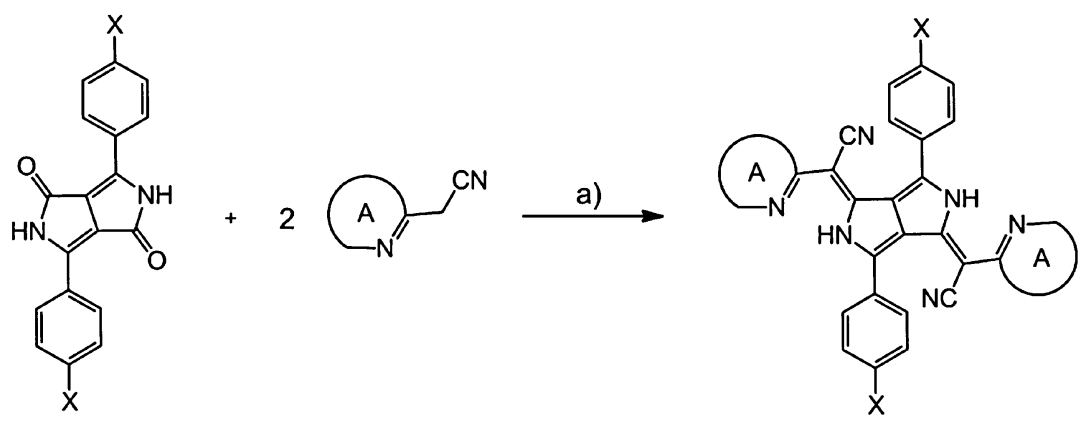

1

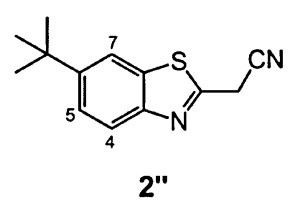

2

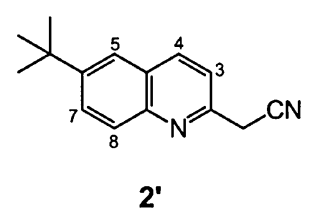

3

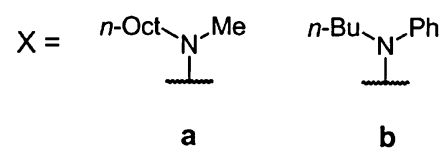

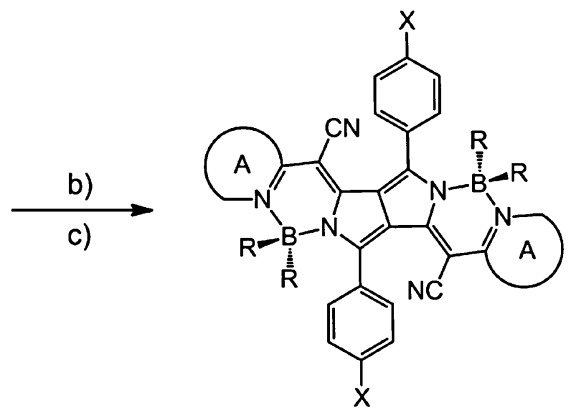

4: $R=F$ 5: $\mathrm{R}=\mathrm{Ph}$

Scheme 1 Reagents and conditions (A = aromatic heterocycle; $\mathrm{X}=$ alkyl- and/or arylamino, alkoxy): (a) anhydrous toluene/POCl 3 , reflux; (b) $\mathrm{CH}_{2} \mathrm{Cl}_{2}$ /diisopropylethylamine, $\mathrm{BF}_{3} \cdot \mathrm{OEt}_{2}$, reflux; (c) $\mathrm{CH}_{2} \mathrm{Cl}_{2} /$ diisopropylethylamine, chlorodiphenylborane, reflux.

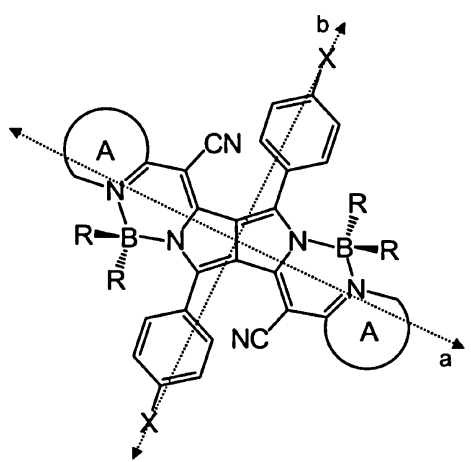

Fig. 1 General structure of PPCy dyes and approximate polarization directions a (long axis) and $\mathrm{b}$ (short axis) of the relevant electronic transitions $(\mathrm{A}=$ aromatic heterocycle; $\mathrm{X}=$ alkyl- and/or arylamino, alkoxy; $\mathrm{R}=\mathrm{F}, \mathrm{Ph})$.

be discussed in comparison to those of the corresponding alkoxy substituted compounds which have already been synthesized. ${ }^{13}$ These are the H-PPCy $\mathbf{3} \mathbf{d}^{\prime}, \mathrm{BF}_{2}-\mathrm{PPCy} \mathbf{4 \mathbf { d } ^ { \prime }}$ and $\mathrm{BPh}_{2}-\mathrm{PPCy} \mathbf{5} \mathbf{d}^{\prime}$ (Scheme 1, $\mathrm{A}=6$-tert-butylquinoline, $\mathrm{X}=n$-octyloxy).

\section{Results and discussion}

\section{Aminophenyl- vs. alkoxyphenyl substituted PPCys}

Four series (i.e. the $\mathrm{H}-\mathrm{PPCy} 3$ and the corresponding $\mathrm{BF}_{2}-\mathbf{4}$ and $\mathrm{BPh}_{2}-\mathrm{PPCys}$ ) of para-aminophenyl substituted compounds have been synthesized using three different aminosubstituents X (Scheme 1): methyloctylamino as a dialkylated amine leading to PPCys 3a, 4a, 5a, $n$-butylphenylamino as an alkylarylated amine leading to PPCys $\mathbf{3 b}, \mathbf{4 b}, \mathbf{5 b}$ and bis-[(paratert-butyl)phenyl]amino as a diarylated amine leading to PPCys 3c, 4c, 5c. Two different heteroaromatic acetonitriles 2 have been used, namely 2-(6-tert-butylbenzothiazol-2-yl)acetonitrile $\mathbf{2}^{\prime \prime}$ (employed only for the dialkylamino substituted compounds) leading to PPCys $\mathbf{3}^{\prime \prime}, \mathbf{4}^{\prime \prime}, \mathbf{5}^{\prime \prime}$ and 2-(6-tert-butylquinoline-2-yl)acetonitrile $\mathbf{2}^{\prime}$ leading to PPCys $\mathbf{3}^{\prime}, \mathbf{4}^{\prime}, \mathbf{5}^{\prime}$.
The different amino substituents were chosen to modify the $\pi$ donor strength of the aminophenyl substituent (for synthesis and characterization of the aminophenyl substituted DPPs 1 see $\mathrm{ESI} \dagger$ ).

Fig. 2a shows the normalized absorption spectra of the $\mathrm{H}-\mathrm{PPCys} \mathbf{3} \mathbf{a}^{\prime}, \mathbf{3} \mathbf{b}^{\prime}$ and $\mathbf{3} \mathbf{c}^{\prime}$ in comparison to the corresponding octyloxyphenyl substituted derivative $\mathbf{3} \mathbf{d}^{\prime}$, all bearing the quinoline moiety. The bands corresponding to the 00 transition of the first electronic transition $\mathrm{S}_{0} \rightarrow \mathrm{S}_{1}$ (in the following named color or $\mathrm{C}$ bands) of the aminophenyl substituted derivatives $\mathbf{3} \mathbf{a}^{\prime}, \mathbf{3} \mathbf{b}^{\prime}$ and $\mathbf{3} \mathbf{c}^{\prime}$ are bathochromically shifted with respect to the alkoxyphenyl substituted derivative $\mathbf{3} \mathbf{d}^{\prime}$. The most remarkable and general difference between the absorptions of the aminophenyl- and the alkoxyphenyl substituted $\mathrm{H}-\mathrm{PPC}$ s are the broad absorptions centered around $20000 \mathrm{~cm}^{-1}$ for the first compounds. We assign these absorptions to charge transfer (CT) transition(s) from the aminophenyl substituent to the main chromophore. The corresponding CT transitions of $3 \mathbf{d}^{\prime}$ - due to the lower donor ability of the alkoxyphenyl group - are centered around $25000 \mathrm{~cm}^{-1}$. In addition to the shifts in energy, the CT bands reach higher intensities in comparison to $\mathbf{3} \mathbf{d}^{\prime}$, i.e. higher charge transfer. Fig. 2a also shows the normalized absorption spectrum of compound $\mathbf{3} \mathbf{a}^{\prime \prime}$ which bears the benzothiazole moiety.

Fig. 2b depicts the normalized absorption spectra of the $\mathrm{BF}_{2}-\mathrm{PPCys} \mathbf{4} \mathbf{a}^{\prime}, \mathbf{4} \mathbf{b}^{\prime}$ and $\mathbf{4} \mathbf{c}^{\prime}$ as compared to the corresponding octyloxyphenyl substituted derivative $\mathbf{4} \mathbf{d}^{\prime}$. Compound $\mathbf{4 a}^{\prime \prime}$ bearing the benzothiazole moiety is also shown. The differences between the absorption energies of the $\mathrm{CT}$ and $\mathrm{C}$ bands $\Delta \tilde{\nu}_{\mathrm{CT}-\mathrm{C}}$ of all aminophenyl substituted $\mathrm{BF}_{2}-\mathrm{PPCys} \mathbf{4}$ are smaller than those of the corresponding octyloxy substituted $\mathrm{BF}_{2}-\mathrm{PPCy} \mathbf{4 d}^{\prime}$. Likewise, a bathochromic shift of the $\mathrm{C}$ bands of the $\mathrm{BF}_{2}-\mathrm{PPCys} \mathbf{4} \mathbf{a}^{\prime}, \mathbf{4} \mathbf{b}^{\prime}, \mathbf{4} \mathbf{c}^{\prime}$ and $\mathbf{4} \mathbf{a}^{\prime \prime}$ with respect to $\mathbf{4} \mathbf{d}^{\prime}$ can be observed, the magnitude of the shifts depending slightly on the nature of the aminosubstituent. Remarkably, the $\Delta \tilde{\nu}_{1 / 2}$ values of the $\mathrm{C}$ bands (FWHM) of $\mathbf{4} \mathbf{a}^{\prime}, \mathbf{4} \mathbf{b}^{\prime}$ and $\mathbf{4} \mathbf{c}^{\prime}$ are much larger than those of octyloxy substituted $\mathrm{BF}_{2}-\mathrm{PPCy}$ 

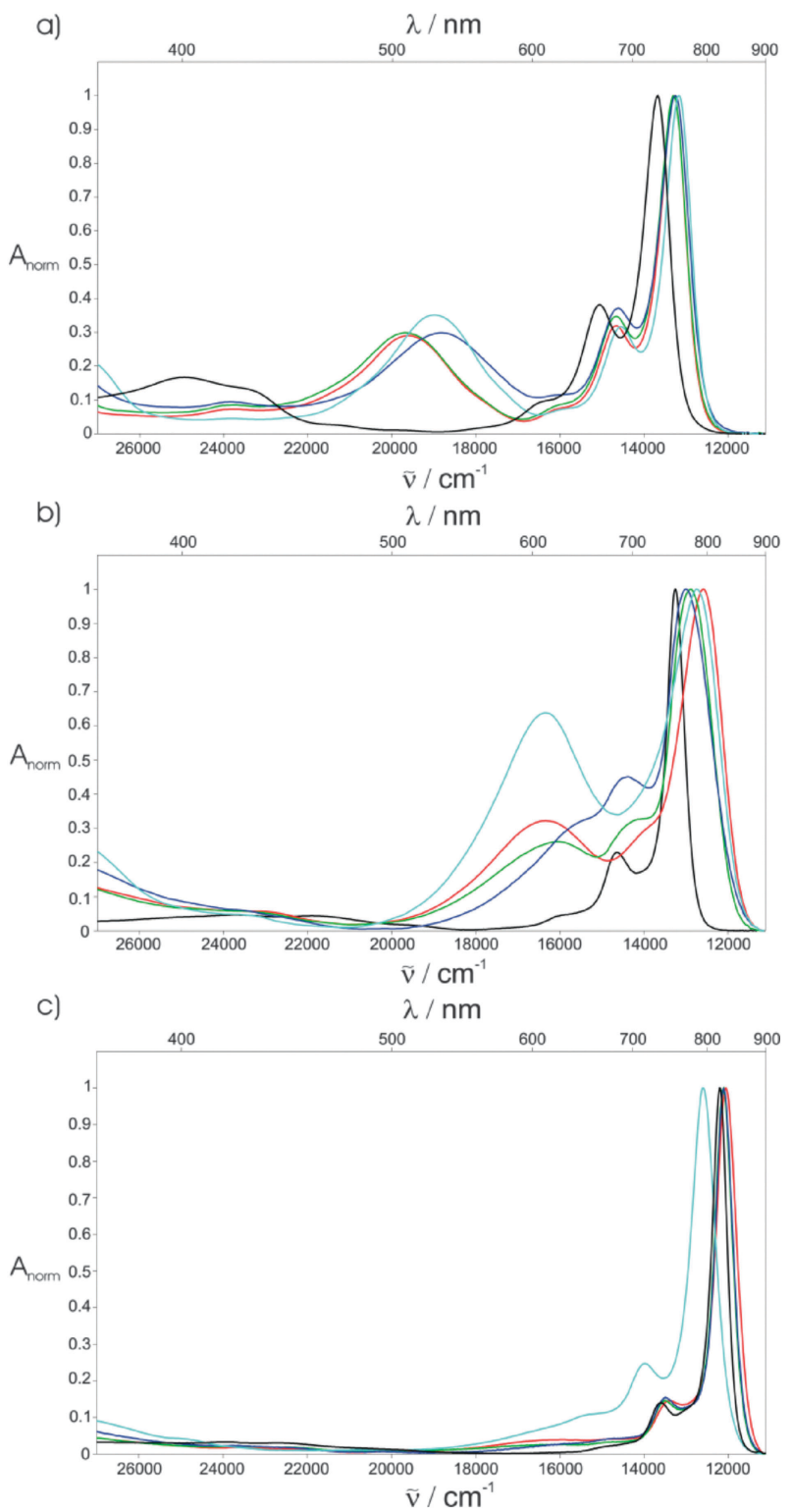

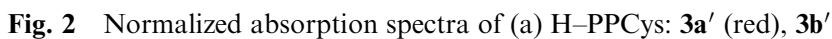

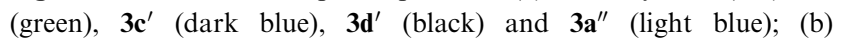
BF 2 -PPCys: $\mathbf{4 a} \mathbf{a}^{\prime}$ (red), $\mathbf{4} \mathbf{b}^{\prime}$ (green), $\mathbf{4} \mathbf{c}^{\prime}$ (dark blue), $\mathbf{4 d ^ { \prime }}$ (black) and

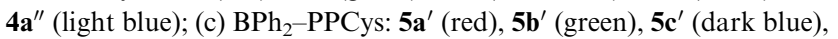
$\mathbf{5} \mathbf{d}^{\prime}$ (black) and 5a' (light blue) in dichloromethane.

$4 \mathbf{d}^{\prime}\left(\Delta \tilde{\nu}_{1 / 2}=530 \mathrm{~cm}^{-1}\right)$, reaching values of around $1200 \mathrm{~cm}^{-1}$. Compound $\mathbf{4} \mathbf{a}^{\prime \prime}$, carrying the benzothiazole component, even reaches a value of almost $1700 \mathrm{~cm}^{-1}$ (Table 1). In contrast to $\mathrm{BF}_{2}-\mathrm{PPCy} \mathbf{4 d}^{\prime}$, which is highly fluorescent $\left(\Phi_{\mathrm{F}}=59 \%\right.$ in $\left.\mathrm{CHCl}_{3}\right),{ }^{13}$ the $\mathrm{BF}_{2}-\mathrm{PPCys} \mathbf{4 a}^{\prime}, \mathbf{4} \mathbf{b}^{\prime}, \mathbf{4} \mathbf{c}^{\prime}$ and $\mathbf{4 a}^{\prime \prime}$ show no detectable fluorescence in dichloromethane at room temperature (Table 1). In order to clarify the influence of the protonation state of the amino functions, protonation experiments have been conducted with $\mathbf{4} \mathbf{a}^{\prime \prime}$ and $\mathbf{4} \mathbf{a}^{\prime}$ using diluted trifluoroacetic acid in dichloromethane. For $\mathbf{4} \mathbf{b}^{\prime}$, which could not be fully protonated in this manner, concentrated sulfuric acid in $n$-butyronitrile was used. $\mathbf{4} \mathbf{c}^{\prime}$ could not be protonated even with sulfuric acid and was decomposed when using larger amounts of acid. Upon protonation of $\mathbf{4 a}^{\prime \prime}$ (absorption $c f$. Fig. 3; for absorption of further protonation experiments see ESI $\dagger$ ), the CT band vanishes and a hypso- and hyperchromically absorbing species is formed simultaneously. The difference between the absorption energies of the $\mathrm{C}$ bands of the protonated and unprotonated form $\Delta \tilde{\nu}_{\mathrm{C}\left(\mathrm{H}^{+}\right)_{-} \mathrm{C}}$ is approximately $800 \mathrm{~cm}^{-1}$. Protonation also leads to reduction of the halfwidth of the $\mathrm{C}$ band to a value of $\Delta \tilde{\nu}_{1 / 2}=530 \mathrm{~cm}^{-1}$ (Table 1), which compares well to that of the octyloxy substituted $\mathrm{BF}_{2}-\mathrm{PPCy} \mathbf{4 d}^{\prime}$. Obviously, there is a successive protonation of the two amino functions. The observed isosbestic points correspond to the transition of the monoprotonated to the bisprotonated systems 4. A similar stepwise protonation behavior is seen in $p$-aminophenyl substituted BODIPY and DPP dyes. ${ }^{17,18}$ Upon protonation, the fluorescence quantum yield of $\mathbf{4 a}^{\prime \prime}$ changes from 0 to $\Phi_{\mathrm{F}}=$ $45 \%$ in the fully protonated form. Thus, fluorescence of this dye can be switched. The $\mathrm{BF}_{2}-\mathrm{PPCys} \mathbf{4 a}^{\prime}$ and $\mathbf{4 b}^{\prime}$ show the same effects upon protonation, i.e. (1) vanishing of the CT band, (2) hypso- and hyperchromic shift of the $\mathrm{C}$ band, (3) reduction of the halfwidth of the $\mathrm{C}$ band and (4) switching of fluorescence. Changing the nature of the amino substituents from alkyl- to arylaminophenyl $\left(\mathbf{4} \mathbf{a}^{\prime}\right.$ to $\left.\mathbf{4 c}^{\prime}\right)$ has only little influence on the optical properties ( $c f$. Table 1). The absorption energy difference of the $\mathrm{CT}$ and $\mathrm{C}$ bands is lower $\left(\Delta \tilde{\nu}_{\mathrm{CT}-\mathrm{C}}=3810 \mathrm{~cm}^{-1}\right.$ for $\mathbf{4} \mathbf{a}^{\prime}$ to $\sim 2500 \mathrm{~cm}^{-1}$ for $\left.\mathbf{4} \mathbf{c}^{\prime}\right)$ and a pronounced difference in the amount of acid necessary for protonation is observed.

Similar experiments have been performed for $\mathrm{BPh}_{2}-\mathrm{PPCys}$. Fig. 2c depicts the normalized absorption spectra of the $\mathrm{BPh}_{2}-\mathrm{PPCys} \mathbf{5} \mathbf{a}^{\prime}, \mathbf{5} \mathbf{b}^{\prime}$ and $\mathbf{5} \mathbf{c}^{\prime}$ in comparison to the corresponding octyloxyphenyl substituted derivative $\mathbf{5} \mathbf{d}^{\prime}$. Compound $\mathbf{5 a} \mathbf{a}^{\prime \prime}$ bearing the benzothiazole moiety is also shown. The differences between the absorption energies of the CT and $\mathrm{C}$ bands $\Delta \tilde{\nu}_{\mathrm{CT}-\mathrm{C}}$ again are around $3000 \mathrm{~cm}^{-1}$, but the CT bands have much lower intensities than those of $\mathrm{BF}_{2}-\mathrm{PPCys}$. The CT band of the benzothiazole substituted $\mathrm{BPh}_{2}-\mathrm{PPCy} \mathbf{5} \mathbf{a}^{\prime \prime}$ is more intense, whereas the intensity of the CT band of the octyloxy substituted $\mathrm{BPh}_{2}-\mathrm{PPCy} \mathbf{5} \mathbf{d}^{\prime}$ is too weak to be determined. The $\mathrm{C}$ bands of $\mathbf{5} \mathbf{a}^{\prime}, \mathbf{5} \mathbf{b}^{\prime}$ and $\mathbf{5} \mathbf{c}^{\prime}$ are shifted bathochromically with respect to that of $\mathbf{5} \mathbf{d}^{\prime}$, the magnitude of this shift again being only slightly dependent on the nature of the aminosubstituent. The halfwidths of the $\mathrm{C}$ bands of $\mathbf{5} \mathbf{a}^{\prime}, \mathbf{5} \mathbf{b}^{\prime}$ and $\mathbf{5} \mathbf{c}^{\prime}$ are slightly larger than that of $\mathbf{5 \mathbf { d } ^ { \prime }}\left(\Delta \tilde{\nu}_{1 / 2}=430 \mathrm{~cm}^{-1}\right)$ reaching values of around $500-600 \mathrm{~cm}^{-1} . \mathbf{5} \mathbf{a}^{\prime \prime}$ shows a FWHM of nearly $700 \mathrm{~cm}^{-1}$ in comparison. While the quinoline substituted $\mathrm{BPh}_{2}-\mathrm{PPCys}$ $\mathbf{5} \mathbf{a}^{\prime}$ and $\mathbf{5} \mathbf{b}^{\prime}$ show higher fluorescence quantum yields than the corresponding $\mathrm{BF}_{2}-\mathrm{PPCys}\left(\Phi_{\mathrm{F}}=3 \%\right.$ and $19 \%$, respectively, versus nonfluorescence), the $\mathrm{BPh}_{2}-\mathrm{PPCy} \mathbf{5 a}^{\prime \prime}$ and $\mathbf{5} \mathbf{c}^{\prime}$ are nonfluorescent at room temperature (Table 1). Upon protonation of $\mathbf{5 a}^{\prime \prime}$ and $\mathbf{5} \mathbf{a}^{\prime}$ with diluted trifluoroacetic acid, the same effects as described above for $\mathrm{BF}_{2}-$ PPCys are observed. Fig. 4 depicts the absorption spectra for the protonation of $5 \mathbf{a}^{\prime}$ : the CT band vanishes and the FWHM of the C band decreases to a value of $\Delta \tilde{\nu}_{1 / 2}=420 \mathrm{~cm}^{-1}$, which is almost equivalent to that of the octyloxy substituted $\mathrm{BPh}_{2}-\mathrm{PPCy} \mathbf{5} \mathbf{d}^{\prime}$ $\left(\Delta \tilde{\nu}_{1 / 2}=430 \mathrm{~cm}^{-1}\right)$. The $\mathrm{C}$ bands are slightly shifted hypsoand hyperchromically $\left(\Delta \tilde{\nu}_{\mathrm{C}\left(\mathrm{H}^{+}\right)-\mathrm{C}}<100 \mathrm{~cm}^{-1}\right)$. The quantum yields reach values of around $33 \%$. 5 $\mathbf{b}^{\prime}$ and $\mathbf{5} \mathbf{c}^{\prime}$ cannot be protonated (concentrated sulfuric acid in $n$-butyronitrile) without decomposition of the compounds. Fig. 4 also shows 
Table 1 Spectroscopic data of the first and second electronic transition of $\mathrm{BF}_{2}-\mathrm{PPCys}(\mathbf{4})$ and $\mathrm{BPh}_{2}-\mathrm{PPCys}(\mathbf{5})$ in unprotonated and protonated $\left(\mathrm{H}^{+}\right)$forms. ${ }^{a} \lambda_{\mathrm{C}}$ : absorption wavelength of the $\mathrm{C}$ band, $\tilde{\nu}_{\mathrm{C}}$ : absorption wavenumber of the $\mathrm{C}$ band, $\varepsilon_{\mathrm{C}}$ : extinction coefficient of the $\mathrm{C}$ band, $\tilde{\nu}_{\mathrm{CT}}$ : absorption wavenumber of the CT band, $\varepsilon_{\mathrm{CT}}$ : extinction coefficient of the CT band, $\Delta \tilde{\nu}_{\mathrm{CT}-\mathrm{C}}$ : difference between the absorption wavenumber of the $\mathrm{CT}$ and the $\mathrm{C}$ band, $\Delta \tilde{\nu}_{\mathrm{C}\left(\mathrm{H}^{+}\right) \mathrm{C}}$ : difference between the absorption wavenumbers of the $\mathrm{C}$ bands of the protonated and unprotonated form, $\Delta \tilde{\nu}_{1 / 2}$ : halfwidth of the $\mathrm{C}$ band, $f$ : oscillator strength, $\lambda_{\mathrm{F}}$ : emission wavelength, $\Phi_{\mathrm{F}}$ : fluorescence quantum yield, $\tau_{\text {calc }}$ : calculated fluorescence lifetime, $\tau_{\text {exp }}$ : experimentally determined fluorescence lifetime

\begin{tabular}{|c|c|c|c|c|c|c|c|c|c|c|c|c|c|}
\hline РPCy & $\lambda_{\mathrm{C}} / \mathrm{nm}$ & $\tilde{\nu}_{\mathrm{C}} / \mathrm{cm}^{-1}$ & $\varepsilon_{\mathrm{C}} / \mathrm{M}^{-1} \mathrm{~cm}^{-1}$ & $\tilde{\nu}_{\mathrm{CT}} / \mathrm{cm}^{-1}$ & $\varepsilon_{\mathrm{CT}} / \mathrm{M}^{-1} \mathrm{~cm}^{-1}$ & $\Delta \tilde{\nu}_{\mathrm{CT}-\mathrm{C}} / \mathrm{cm}^{-1}$ & $\Delta \tilde{\nu}_{\mathrm{C}\left(\mathrm{H}^{+}\right)-\mathrm{C}} / \mathrm{cm}^{-1}$ & $\Delta \tilde{\nu}_{1 / 2} / \mathrm{cm}^{-1}$ & $f$ & $\lambda_{\mathrm{F}} / \mathrm{nm}$ & $\Phi_{\mathrm{F}} / \%$ & $\tau_{\text {calc }} / \mathrm{ns}$ & $\tau_{\exp } / \mathrm{ns}$ \\
\hline $4 a^{\prime \prime}$ & 786 & 12720 & 67000 & 16290 & 43000 & 3570 & - & 1670 & - & - & 0 & - & - \\
\hline $\mathbf{4 a}^{\prime \prime}\left(\mathrm{H}^{+}\right)$ & 738 & 13550 & 169000 & - & 0 & - & 830 & 530 & 0.77 & 750 & 45 & 3.70 & 3.23 \\
\hline $4 a^{\prime}$ & 795 & 12580 & 96000 & 16390 & 32000 & 3810 & - & 1260 & - & - & 0 & - & - \\
\hline $\mathbf{4} \mathbf{a}^{\prime}\left(\mathrm{H}^{+}\right)$ & 755 & 13250 & 217000 & - & 0 & - & 670 & 430 & 0.81 & 770 & 51 & 4.18 & 3.70 \\
\hline $4 b^{\prime}$ & 770 & 12990 & 93000 & 16180 & 24000 & 3190 & - & 1180 & - & - & 0 & - & - \\
\hline $\mathbf{4} \mathbf{b}^{\prime}\left(\mathrm{H}^{+}\right)$ & 751 & 13320 & 208000 & - & 0 & - & 330 & 450 & 0.81 & 760 & 46 & 4.01 & 3.60 \\
\hline $\mathbf{4} c^{\prime}$ & 770 & 12990 & 110000 & $\sim 15500$ & $\sim 20000^{b}$ & $\sim 2500$ & - & 1260 & - & - & 0 & - & - \\
\hline $5 a^{\prime \prime}$ & 794 & 12600 & 145000 & $\sim 16000$ & 12000 & $\sim 3400$ & - & 680 & - & - & 0 & - & - \\
\hline $5 \mathbf{a}^{\prime \prime}\left(\mathrm{H}^{+}\right)$ & 800 & 12500 & 192000 & - & 0 & - & $<100$ & 500 & 0.75 & 810 & 33 & 3.98 & 3.11 \\
\hline $\mathbf{5} \mathbf{a}^{\prime}$ & 829 & 12060 & 192000 & $\sim 16000$ & 10000 & $\sim 3900$ & - & 580 & - & 854 & 3 & - & - \\
\hline $\mathbf{5} \mathbf{a}^{\prime}\left(\mathrm{H}^{+}\right)$ & 824 & 12140 & 239000 & - & 0 & - & $<100$ & 420 & 0.76 & 834 & 33 & 3.05 & 3.30 \\
\hline $5 \mathbf{b}^{\prime}$ & 825 & 12120 & 209000 & $\sim 16000$ & $<10000$ & $\sim 3900$ & - & 500 & - & 843 & 19 & - & - \\
\hline $5 c^{\prime}$ & 826 & 12110 & 206000 & $\sim 16000$ & $<10000$ & $\sim 3900$ & - & 500 & - & - & 0 & - & - \\
\hline
\end{tabular}

${ }^{a}$ Conditions: dichloromethane (trifluoroacetic acid for protonation); in the case of $\mathbf{4} \mathbf{b}^{\prime}: n$-butyronitrile (conc. sulfuric acid for protonation).

${ }^{b}$ Deconvoluted.

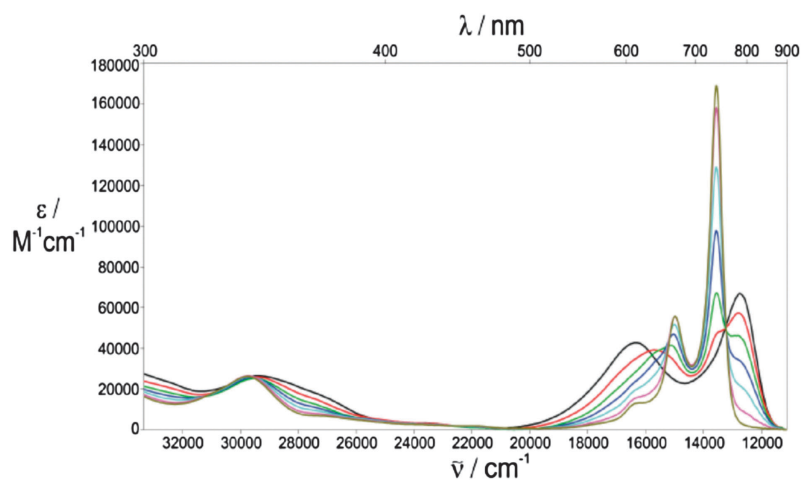

Fig. 3 Absorption spectra for the protonation of $\mathbf{4 a}^{\prime \prime}$ in dichloromethane using diluted trifluoroacetic acid; $\mathbf{4 a} \mathbf{a}^{\prime \prime}$ unprotonated (black), successive addition of acid to $\mathbf{4} \mathbf{a}^{\prime \prime}$ (in the order: red, green, dark blue, light blue, magenta), $\mathbf{4 a}$ " fully protonated (olive).

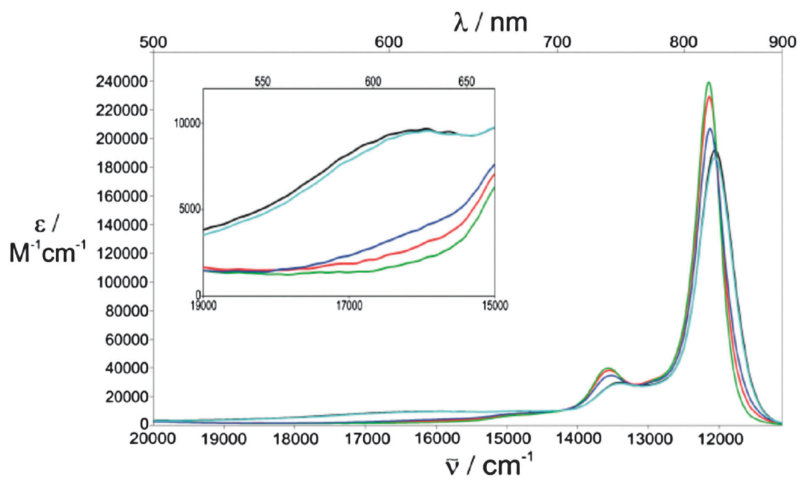

Fig. 4 Absorption spectra for the protonation of $\mathbf{5 a}^{\prime}$ in dichloromethane using diluted trifluoroacetic acid; $\mathbf{5} \mathbf{a}^{\prime}$ unprotonated (black), addition of acid to $\mathbf{5 \mathbf { a } ^ { \prime }}$ (red), $\mathbf{5} \mathbf{a}^{\prime}$ fully protonated (green); subsequent addition of triethylamine to fully protonated $\mathbf{5} \mathbf{a}^{\prime}$ (dark blue) finally recovers the absorption of starting compound $\mathbf{5} \mathbf{a}^{\prime}$ (light blue), serving as a reversibility proof. The inset highlights the absorption of the CT band. that the protonation of the aminophenyl substituted PPCys is reversible. The protonated form of $\mathbf{5 a}^{\prime}$ was titrated with diluted triethylamine and absorption of the unprotonated starting compound was recovered.

In order to validate the fluorescence quantum yield measurements, fluorescence lifetimes $\tau$ of the protonated aminophenyl substituted $\mathrm{BF}_{2}-\mathrm{PPCys} \mathbf{4} \mathbf{a}^{\prime \prime}, \mathbf{4} \mathbf{a}^{\prime}, \mathbf{4} \mathbf{b}^{\prime}$ and $\mathrm{BPh}_{2}-\mathrm{PPCys} \mathbf{5} \mathbf{a}^{\prime \prime}, \mathbf{5} \mathbf{a}^{\prime}$ have been determined via time correlated single photon counting (TCSPC) in dichloromethane (except for $\mathbf{4 b}^{\prime}$ : $n$-butyronitrile). These are the derivatives which can be protonated completely without destruction of the chromophore. A pulsed excitation laser at a wavelength of $635 \mathrm{~nm}$ and a repetition rate of $10 \mathrm{MHz}$ was employed. Several lifetimes for different concentrations of each dye were measured and a linear regression was made to remove reemission effects. ${ }^{19} \tau$ is obtained from an extrapolation of the concentration against zero. The experimentally determined lifetimes $\left(\tau_{\exp }\right)$ are compared to calculated lifetimes $\left(\tau_{\text {calc }}\right)$. Lifetimes were calculated using the experimentally determined fluorescence quantum yields $\Phi_{\mathrm{F}}$ obtained by comparison with a standard and the relation given in (1).

$$
\tau_{\text {calc }}=\frac{\Phi_{\mathrm{F}}}{k_{\mathrm{F}}}
$$

Radiative rate constants $k_{\mathrm{F}}$ were calculated using the StricklerBerg relation (2), ${ }^{20}$

$$
k_{\mathrm{F}}=2.88 \times 10^{-9} \frac{\int I_{\mathrm{F}}(\tilde{\nu}) \mathrm{d} \tilde{\nu}}{\int \tilde{\nu}^{-3} I_{\mathrm{F}}(\tilde{\nu}) \mathrm{d} \tilde{\nu}} \int \varepsilon \mathrm{d} \ln \tilde{\nu}
$$

where $\int I_{\mathrm{F}}(\tilde{\nu}) \cdot \mathrm{d} \tilde{\nu}$ is the integral of the fluorescence intensity against wavenumbers and $\varepsilon$ is the molar extinction coefficient. The calculated values deviate from the experimentally determined ones by $8-28 \%$. Considering that eqn (2) is strictly only valid for systems where no geometry change of excited and ground states occurs, the calculated and experimentally determined values for $\tau$ match reasonably well. The lifetimes are shorter for the $\mathrm{BPh}_{2}-\mathrm{PPCys} \mathbf{5 a}^{\prime \prime}(\tau=3.11 \mathrm{~ns})$ and 


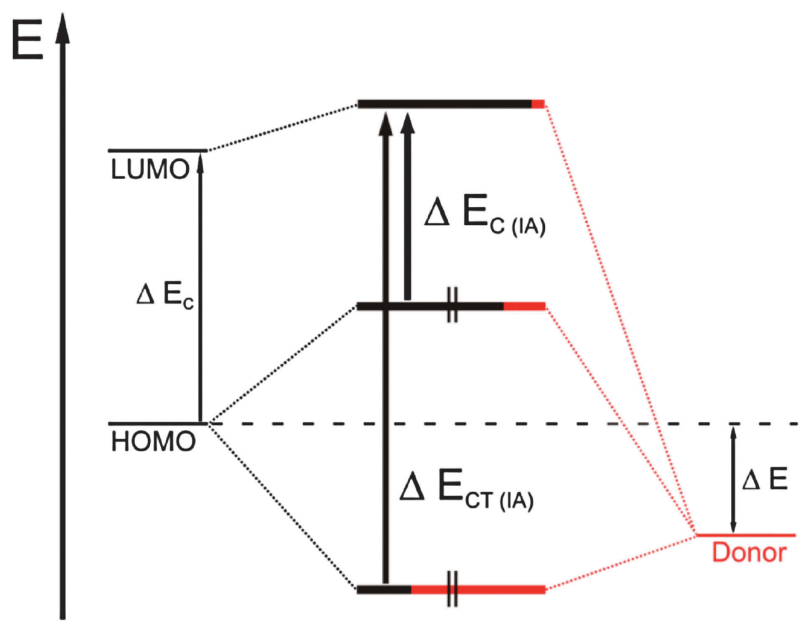

Fig. 5 Frontier orbitals and characteristic transitions after interaction of the chromophoric main system with aminophenyl substituents; $\Delta E_{\mathrm{C}}=$ energy difference corresponding to the $\mathrm{C}$ band, $\Delta E_{\mathrm{C}(\mathrm{IA})}=$ energy difference corresponding to the $\mathrm{C}$ band with interaction of energy levels, $\Delta E_{\mathrm{CT}(\mathrm{IA})}=$ energy difference corresponding to the CT band with interaction of energy levels, $\Delta E=$ energy difference between HOMO and donor level.

$\mathbf{5} \mathbf{a}^{\prime}(\tau=3.30 \mathrm{~ns})$ than for the corresponding BF 2 -PPCys $\mathbf{4 a}^{\prime \prime}$ ( $\tau=3.23 \mathrm{~ns})$ and $\mathbf{4} \mathbf{a}^{\prime}(\tau=3.70 \mathrm{~ns})$ as shown in Table 1 . The fluorescence lifetimes determined thus support the unusually high fluorescence quantum yield measurements reported for PPCys (up to $70 \%$ in the case of alkoxy- ${ }^{13}$ or up to $51 \%$ for aminophenyl substituted PPCys).

\section{Interpretation}

The PPCys reported above can be regarded as chromophores (long axis, $c f$. Fig. 1) to which electron donors were added (short axis). Whereas the first electronic transition is polarized along the long axis, we assign the subsequent absorptions (at shorter wavelengths) as transitions with high charge transfer character, originating from the donors and consequently polarized along the short axis. Depending on the donor strength different effects are observed. Fig. 5 shows a simplified energy scheme serving for the interpretation of the observed effects on the absorption spectra. The $\mathrm{C}$ band corresponds to a rather pure HOMO-LUMO transition $\left(\Delta E_{\mathrm{C}}\right)$. The transition causing the CT band $\left(\Delta E_{\mathrm{CT}(\mathrm{IA})}\right.$; index IA to indicate the inclusion of interaction), by contrast, originates from an orbital with large coefficients at the donor. The aminophenyl substituted PPCys contain stronger donors than the corresponding alkoxyphenyl substituted derivatives, i.e. their donor orbitals are higher in energy. Fig. 2a shows that the CT bands of the aminophenyl substituted H-PPCys $\mathbf{3} \mathbf{a}^{\prime}$, $\mathbf{3} \mathbf{b}^{\prime}$ and $\mathbf{3} \mathbf{c}^{\prime}$ are redshifted in comparison to the CT band of the corresponding octyloxyphenyl substituted H-PPCy $\mathbf{3} \mathbf{d}^{\prime}$, indicating that $\Delta E_{\mathrm{CT}(\mathrm{IA})}$ decreases for stronger donors. If the energy difference between the HOMO and donor level $(\Delta E)$ is small, mixing of the energy levels will lead to a rise of the HOMO and LUMO energies and lowering of the donor level. Since the LUMO is higher in energy, it will be raised less, which leads to a decrease of the energy difference that causes the $\mathrm{C}$ band $\left(\Delta E_{\mathrm{C}(\mathrm{IA})}\right)$. This means that the $\mathrm{C}$ band will be shifted bathochromically if a donor is added to the chromophore. The magnitude of this shift depends on the strength of coupling of the donor to the chromophore, which is dominated by the energy difference between HOMO and donor level $(\Delta E)$ and the orbital coefficients at the atoms linking the donor and the chromophoric system. The CT band intensity correlates with the electron affinity, being high in the case of $\mathrm{BF}_{2}-\mathrm{PPCys}$ compared to $\mathrm{BPh}_{2}-\mathrm{PPCys}$. The described bathochromic shift of the $\mathrm{C}$ bands with respect to the octyloxyphenyl substituted $\mathrm{BF}_{2}-\mathrm{PPCy} \mathbf{4} \mathbf{d}^{\prime}$, which contains a very weak donor, can be seen in the absorption spectra of the aminophenyl substituted $\mathrm{BF}_{2}-\mathrm{PPCys} \mathbf{4} \mathbf{a}^{\prime}, \mathbf{4} \mathbf{b}^{\prime}$ and $\mathbf{4 c}^{\prime}$ (and also $\mathbf{4 a}^{\prime \prime}$ which bears a different heterocycle) in Fig. 2b. Altering the donor strength via different substituents at the amino function (dialkylamino for $\mathbf{4} \mathbf{a}^{\prime}$, alkylarylamino for $\mathbf{4} \mathbf{b}^{\prime}$ and diarylamino for $\mathbf{4 c}^{\prime}$ ) has only little effect on the bathochromic shift. A major change, however, is induced upon protonation of the amino-function. Protonation leads to a loss of its + M-effect. The protonated $\mathrm{BF}_{2}-\mathrm{PPCys} \mathbf{4}$ therefore represent forms in which the efficient CT transition(s) has (have) been switched off. The energy difference between the $\mathrm{C}$ bands of the protonated and unprotonated form $\Delta \tilde{\nu}_{\mathrm{C}_{\left(\mathrm{H}^{+}\right)}{ }_{\mathrm{C}}}$ (Table 1) can thus be taken as a measure for the strength of donor-chromophore coupling.

While the bonds linking the substituted phenyl groups to the chromophore exhibit partial double bond character, they do not lead to rigid structures. Many rotamers exist which contribute to the FWHM of the CT band. The different rotamers will also feature different mixing of energy levels, so that an effect on the $\mathrm{C}$ band can be expected. As derived from Fig. $2 \mathrm{~b}$ and Table 1, the FWHM of the $\mathrm{C}$ bands of the aminophenyl substituted $\mathrm{BF}_{2}-\mathrm{PPCys} \mathbf{4} \mathbf{a}^{\prime}, \mathbf{4} \mathbf{b}^{\prime}$ and $\mathbf{4 c}^{\prime}$ (also $\mathbf{4} \mathbf{a}^{\prime \prime}$ ) are much larger than those of the corresponding octyloxyphenyl substituted derivative $\mathbf{4} \mathbf{d}^{\prime}$. Upon elimination of the strong donor through protonation of the amino function, the halfwidths of the $\mathrm{C}$ bands are reduced to values which match those of the corresponding alkoxyphenyl substituted $\mathrm{BF}_{2}-\mathrm{PPCy} \mathbf{4 d}^{\prime}$ $\left(\Delta \tilde{\nu}_{1 / 2} \approx 500 \mathrm{~cm}^{-1}\right)$ almost perfectly. Since coupling of the donor to the chromophore is strong in the case of the aminophenyl substituted $\mathrm{BF}_{2}-\mathrm{PPCy}$, torsional motion about the bond linking these two systems in the $\mathrm{S}_{1}$ state might be an effective pathway for radiationless deactivation of the first electronic excited state. It is found that the unprotonated forms of $\mathbf{4} \mathbf{a}^{\prime}, \mathbf{4} \mathbf{b}^{\prime}, \mathbf{4} \mathbf{c}^{\prime}$ and $\mathbf{4} \mathbf{a}^{\prime \prime}$ show, in the limit of our detection method, no fluorescence at room temperature. If coupling of the donor to the chromophore is eliminated through protonation of the amino function, torsion about the described bond can no longer be effective in depopulating $\mathrm{S}_{1}$. The quantum yields of the protonated forms of $\mathbf{4} \mathbf{a}^{\prime}, \mathbf{4} \mathbf{b}^{\prime}$ and $\mathbf{4} \mathbf{a}^{\prime \prime}$ therefore increase to values of around $50 \%$ (4c' cannot be protonated).

In the case of the aminophenyl substituted $\mathrm{BPh}_{2}-\mathrm{PPCys} \mathbf{5} \mathbf{a}^{\prime}$, $\mathbf{5} \mathbf{b}^{\prime}$ and $\mathbf{5} \mathbf{c}^{\prime}$ the described effects on the $\mathrm{S}_{0} \rightarrow \mathrm{S}_{1}$ band are less pronounced. Although the energy differences of the CT and the $\mathrm{C}$ bands in wavenumbers $\Delta \tilde{\nu}_{\mathrm{CT}-\mathrm{C}}$ are in the same range as for $\mathrm{BF}_{2}-\mathrm{PPCy}$ (around $3000 \mathrm{~cm}^{-1}$ ), the coupling of the donors is less efficient in the case of $\mathrm{BPh}_{2}-\mathrm{PPCys}$ due to a greater energy difference between HOMO and donor level $(\Delta E)$. Only $\mathbf{5} \mathbf{a}^{\prime \prime}$ shows a higher intensity for the CT band. 
As described above, the FWHM of the $\mathrm{C}$ bands of the unprotonated forms of $\mathbf{5 a}^{\prime}, \mathbf{5} \mathbf{b}^{\prime}$ and $\mathbf{5 c}^{\prime}$ are in the range of $500-600 \mathrm{~cm}^{-1}$ and thus are only slightly higher than in the protonated forms. The energy differences between the $\mathrm{C}$ bands of the protonated and unprotonated forms $\left.\Delta \tilde{\nu}_{\mathrm{C}} \mathrm{H}^{+}\right) \mathrm{C}$ of $\mathbf{5 a}^{\prime \prime}$ and $\mathbf{5} \mathbf{a}^{\prime}$ are less than $100 \mathrm{~cm}^{-1}$. These values underline that the donor-chromophore coupling is comparatively weak for $\mathrm{BPh}_{2}-\mathrm{PPCys}$. Hence the quantum yields reach higher values already for the unprotonated forms of $\mathbf{5 a}^{\prime}\left(\Phi_{\mathrm{F}}=3 \%\right)$ and $\mathbf{5} \mathbf{b}^{\prime}$ $\left(\Phi_{\mathrm{F}}=19 \%\right)$. Yet, $\mathbf{5 a}^{\prime \prime}$, which has a higher intensity for the CT band, shows a diminished value of $\Phi_{\mathrm{F}}=0$. Upon protonation and thus elimination of the donor, the quantum yields reach values of around $33 \%$ for $\mathbf{5} \mathbf{a}^{\prime \prime}$ and $\mathbf{5} \mathbf{a}^{\prime}\left(\mathbf{5} \mathbf{b}^{\prime}\right.$ and $\mathbf{5} \mathbf{c}^{\prime}$ cannot be protonated).

\section{Conclusions}

In order to investigate the effects of substituents at the DPP core of PPCys, four series of aminophenyl substituted PPCys (H-PPCys 3 and the corresponding $\mathrm{BF}_{2}-$ and $\mathrm{BPh}_{2}-\mathrm{PPCys}^{4}$ and $\mathbf{5}$, respectively) have been synthesized and their photophysical properties were studied.

Three series in which the nature of the aminogroup was varied and a fourth series containing a different heterocyclic end group were compared. In general, aminophenyl substituted PPCys exhibit higher electronic transitions which are more intense and long wavelength-shifted compared to those of the corresponding alkoxyphenyl substituted analogues. These transitions are interpreted as $\mathrm{CT}$ transitions originating from a stronger donor behavior of amino- $v s$. alkoxyphenyl substituents. Several effects on the $S_{0} \rightarrow S_{1}$ band of these dyes can be observed arising from the coupling of the donor to the main chromophore. The $\mathrm{C}$ band ( 00 transition of the $\mathrm{S}_{0} \rightarrow \mathrm{S}_{1}$ band) is shifted bathochromically by insertion of a donor, the halfwidths are increased, and fluorescence quantum yields are greatly reduced. Upon protonation, the observable effects are (1) vanishing of the long wavelength $\mathrm{CT}$ absorptions, (2) hypso- and hyperchromic shift of the $\mathrm{C}$ band, (3) reduction of the FWHM of the C absorption band, and (4) recovery of fluorescence emission. The effects are less pronounced in the case of $\mathrm{BPh}_{2}-\mathrm{PPCys}$. With this work a better understanding of the interplay between the main chromophore (long axis) and the substituents at the DPP core in the short axis of PPCys was achieved. The ability of fluorescence switching could serve as a basis for the developing of $\mathrm{pH}$ sensitive fluorescence indicators with electronic transitions in the near infrared.

\section{Experimental}

\section{General}

Solvents were purified and dried according to standard procedures. All commercially available reagents were used without further purification unless otherwise noted. Column chromatography was performed on Roth silica gel $60(40-63 \mu \mathrm{m})$. All solvents used for UV/Vis/NIR and fluorescence measurements were of spectroscopic grade. NMR spectra were recorded with a Bruker Avance III-400 (400 MHz). The residual solvent peak was used as internal reference $\left(\mathrm{CHCl}_{3}: \delta=7.26 \mathrm{ppm}\right.$;
$\mathrm{C}_{2} \mathrm{DHCl}_{4}: \delta=5.91 \mathrm{ppm}$ ). For ${ }^{1} \mathrm{H}$ NMR, multiplicity ( $\mathrm{s}=$ singlet, $\mathrm{d}=$ doublet, $\mathrm{dd}=$ doublet of doublet, $\mathrm{t}=$ triplet, $\mathrm{q}=$ quartet, quint $=$ quintet, sext $=$ sextet, $\mathrm{m}=$ multiplet, $\mathrm{b}=$ broad signal) and coupling constants are reported whenever possible. Numbering of the atoms for assignment of the resonances is shown in Scheme 1. $A A^{\prime}$ and $X X^{\prime}$ designate the protons attached to the phenyl groups at the DPP core. ESI-ion trap mass spectra were recorded in 1,4-dioxane with a Bruker Esquire 3000 plus in positive mode. Elemental analysis was performed with a CHN analyser Vario EL from Elementar. Absorption and emission spectra were recorded at ambient temperature by using $1 \mathrm{~cm}$ quartz cuvettes $(3 \mathrm{~mL})$. UV/Vis/NIR absorptions were recorded with a Varian spectrometer, model Cary 50; the spectra were processed with Spekwin $^{21}$ to calculate the oscillator strength. Fluorescence spectra were recorded with a self-assembled NIR fluorescence spectrometer with a nitrogen-cooled Ge diode (Northcoast) as detector. A diode laser $(690 \mathrm{~nm}, 19 \mathrm{~mW}$, model ACM19/1203) was used for excitation. $\mathrm{BF}_{2}-\mathrm{PPCy} \mathbf{4 \mathbf { d } ^ { \prime }}\left(\Phi_{\mathrm{F}}=0.54\right.$ in $\left.\mathrm{CH}_{2} \mathrm{Cl}_{2}\right)$ was used as reference to determine the quantum yield. Due to the assumption that aminophenyl substituted PPCys may be less basic in the electronic excited rather than the ground state, as it is often found in donor substituted aromatics, ${ }^{22}$ quantum yields of the protonated PPCys were determined not only after complete protonation but also with an excess of acid until the values for $\Phi_{\mathrm{F}}$ did not change anymore. Fluorescence lifetimes were determined using the TCSPC module PicoHarp 300 (PicoQuant, Germany) with an integrated histogrammer in the TTTR mode. A single-mode fiber laser, model LDH-D-C635 (PicoQuant, Germany), with a wavelength of 634-638 nm was employed. The excitation intensity was adjusted in a manner that the count rates were below $10^{5} \mathrm{cts} \mathrm{s}^{-1}$. Synthesis and physical data of $\mathbf{2}^{\prime \prime}$ and $\mathbf{2}^{\prime}$ have already been published. ${ }^{13}$

\section{General procedure for the synthesis of H-PPCy dyes 3}

DPP $1(1 \mathrm{mmol})$ and heteroarylacetonitrile $2(2.5 \mathrm{mmol})$ were heated to reflux in anhydrous toluene under nitrogen. Phosphoryl chloride $(8 \mathrm{mmol})$ was then added. The reaction was monitored by UV/Vis/NIR spectroscopic analysis and thin layer chromatography. As soon as either $\mathbf{1}$ was used up or the concentration of the short-wavelength absorbing byproducts increased, the reaction was stopped. The solvent and excess phosphoryl chloride were removed under vacuum, the crude product was dissolved in dichloromethane and washed with saturated, aqueous $\mathrm{NaHCO}_{3}$ solution. The solvent was again removed under vacuum and the crude product was treated with methanol in an ultrasonic bath. The solid was collected by filtration and washed with methanol until the filtrate became colorless. If sufficiently soluble, the remaining solid was purified by column chromatography.

\section{Compound 3a"}

Column chromatography (petroleum ether $/ \mathrm{CH}_{2} \mathrm{Cl}_{2}, 1: 3$ ) afforded $3 \mathbf{a}^{\prime \prime}$ as a dark violet solid in $18 \%$ yield. ${ }^{1} \mathrm{H}$ NMR (400 MHz, $\mathrm{C}_{2} \mathrm{D}_{2} \mathrm{Cl}_{4}$ ): $\delta=13.15(\mathrm{~s}, 2 \mathrm{H}, \mathrm{NH}), 7.85-7.56(\mathrm{~b}, 8 \mathrm{H}$, $4 \mathrm{H} \mathrm{AA}^{\prime}, 4 \mathrm{H}$ benzothiazole), 7.45 (b, $2 \mathrm{H}$, benzothiazole), 6.82 (b, $\left.4 \mathrm{H}, \mathrm{XX}^{\prime}\right), 3.38$ (b, $4 \mathrm{H}, \mathrm{NCH}_{2}$ ), $3.04\left(\mathrm{~s}, 6 \mathrm{H}, \mathrm{NCH}_{3}\right), 1.59$ (b, $\left.4 \mathrm{H}, \mathrm{NCH}_{2} \mathrm{CH}_{2}\right), 1.35-1.18(\mathrm{~b}, 38 \mathrm{H}, 18 \mathrm{H} t-\mathrm{BuH}, 20 \mathrm{H}$ 
$\left.\mathrm{N}\left(\mathrm{CH}_{2}\right)_{2}\left(\mathrm{CH}_{2}\right)_{5}\right), 0.82\left(\mathrm{~b}, 6 \mathrm{H}, \mathrm{N}\left(\mathrm{CH}_{2}\right)_{7} \mathrm{CH}_{3}\right) . \mathrm{UV} / \mathrm{Vis} / \mathrm{NIR}$ $\left(\mathrm{CH}_{2} \mathrm{Cl}_{2}\right): \lambda_{\max }(\varepsilon)=760(120000), 687$ (38000), 526 (42000 $\mathrm{M}^{-1} \mathrm{~cm}^{-1}$ ) nm. ESI-MS (\%): calcd. for $\mathrm{C}_{62} \mathrm{H}_{75} \mathrm{~N}_{8} \mathrm{~S}_{2}$ $[\mathrm{M}+\mathrm{H}]^{+}$995.6; found 995.5. Elemental analysis (\%): $\mathrm{C}_{62} \mathrm{H}_{74} \mathrm{~N}_{8} \mathrm{~S}_{2}$ (995.43): calcd. C 74.81, H 7.49, N 11.26, S 6.44; found C 74.68, H 7.48, N 11.18, S 6.30 .

\section{Compound $3 \mathbf{a}^{\prime}$}

Column chromatography $\left(\mathrm{CH}_{2} \mathrm{Cl}_{2} /\right.$ ethyl acetate, $\left.10: 1\right)$ afforded $3 \mathbf{a}^{\prime}$ as a dark violet solid in $13 \%$ yield. ${ }^{1} \mathrm{H}$ NMR $\left(400 \mathrm{MHz}, \mathrm{C}_{2} \mathrm{D}_{2} \mathrm{Cl}_{4}, 100{ }^{\circ} \mathrm{C}\right): \delta=14.42(\mathrm{~s}, 2 \mathrm{H}, \mathrm{NH})$, 8.20-7.60 (b, $14 \mathrm{H}, 4 \mathrm{H} \mathrm{AA}^{\prime}, 10 \mathrm{H}$ chinoline), 6.94 (b, $4 \mathrm{H}$, $\mathrm{XX}^{\prime}$ ), 3.49 (b, $4 \mathrm{H}, \mathrm{NCH}_{2}$ ), 3.15 (b, $\left.6 \mathrm{H}, \mathrm{NCH}_{3}\right), 1.74$ (b, $4 \mathrm{H}$, $\left.\mathrm{NCH}_{2} \mathrm{CH}_{2}\right), 1.51-1.33(\mathrm{~m}, 38 \mathrm{H}, 18 \mathrm{H} t-\mathrm{BuH}, 20 \mathrm{H}$ $\left.\mathrm{N}\left(\mathrm{CH}_{2}\right)_{2}\left(\mathrm{CH}_{2}\right)_{5}\right), 0.94$ (b, $\left.6 \mathrm{H}, \mathrm{N}\left(\mathrm{CH}_{2}\right)_{7} \mathrm{CH}_{3}\right)$. UV/Vis/NIR $\left(\mathrm{CH}_{2} \mathrm{Cl}_{2}\right): \lambda_{\max }(\varepsilon)=754(134000), 682(43000), 510$ (39000 $\mathrm{M}^{-1} \mathrm{~cm}^{-1}$ ) nm. ESI-MS (\%): calcd. for $\mathrm{C}_{66} \mathrm{H}_{79} \mathrm{~N}_{8}$ $[\mathrm{M}+\mathrm{H}]^{+}$983.6; found 983.9. Elemental analysis (\%): $\mathrm{C}_{66} \mathrm{H}_{78} \mathrm{~N}_{8}$ (983.38): calcd. C 80.61, H 7.99, N 11.39; found C 79.82, H 8.22, N 11.07.

\section{Compound $3 \mathbf{b}^{\prime}$}

Column chromatography $\left(\mathrm{CH}_{2} \mathrm{Cl}_{2} /\right.$ ethyl acetate, $\left.100: 1\right)$ afforded $\mathbf{3} \mathbf{b}^{\prime}$ as a dark violet solid in $17 \%$ yield. ${ }^{1} \mathrm{H}$ NMR $\left(400 \mathrm{MHz}, \mathrm{C}_{2} \mathrm{D}_{2} \mathrm{Cl}_{4}\right): \delta=14.70(\mathrm{~s}, 2 \mathrm{H}, \mathrm{NH}), 7.99(\mathrm{~m}, 2 \mathrm{H}$, chinoline), 7.77-7.57 (m, $12 \mathrm{H}, 4 \mathrm{H} \mathrm{AA}^{\prime}, 8 \mathrm{H}$ chinoline), 7.40 $(\mathrm{m}, 4 \mathrm{H}, \mathrm{NPhH}), 7.26(\mathrm{~m}, 4 \mathrm{H}, \mathrm{NPhH}), 7.19(\mathrm{~m}, 2 \mathrm{H}, \mathrm{NPhH})$, $6.97\left(\mathrm{~m}, 4 \mathrm{H}, \mathrm{XX}^{\prime}\right), 3.77\left(\mathrm{t},{ }^{3} \mathrm{~J}=7.3 \mathrm{~Hz}, 4 \mathrm{H}, \mathrm{NCH}_{2}\right), 1.68$ (quint, $\left.{ }^{3} J=7.3 \mathrm{~Hz}, 4 \mathrm{H}, \mathrm{NCH}_{2} \mathrm{CH}_{2}\right), 1.36(\mathrm{~m}, 22 \mathrm{H}, 4 \mathrm{H}$ $\mathrm{N}\left(\mathrm{CH}_{2}\right)_{2} \mathrm{CH}_{2}, 18 \mathrm{H} t$-BuH), $0.91\left(\mathrm{t},{ }^{3} J=7.3 \mathrm{~Hz}, 6 \mathrm{H}\right.$, $\left.\mathrm{N}\left(\mathrm{CH}_{2}\right)_{3} \mathrm{CH}_{3}\right) . \quad \mathrm{UV} / \mathrm{Vis} / \mathrm{NIR}\left(\mathrm{CH}_{2} \mathrm{Cl}_{2}\right): \lambda_{\max }(\varepsilon)=752$ (141 000), 683 (49 000), $509\left(42000 \mathrm{M}^{-1} \mathrm{~cm}^{-1}\right) \mathrm{nm}$. ESI-MS (\%): calcd. for $\mathrm{C}_{68} \mathrm{H}_{67} \mathrm{~N}_{8}[\mathrm{M}+\mathrm{H}]^{+}$995.6; found 995.8. Elemental analysis (\%): $\mathrm{C}_{68} \mathrm{H}_{66} \mathrm{~N}_{8}$ (995.31): calcd. C 82.06, H 6.68, N 11.26; found C 81.54, H 6.41, N 11.18.

\section{Compound $3 \mathrm{c}^{\prime}$}

Column chromatography $\left(\mathrm{CH}_{2} \mathrm{Cl}_{2} /\right.$ ethyl acetate, $\left.100: 1\right)$ afforded $3 \mathbf{c}^{\prime}$ as a dark violet solid in $6 \%$ yield. ${ }^{1} \mathrm{H}$ NMR $\left(400 \mathrm{MHz}, \mathrm{C}_{2} \mathrm{D}_{2} \mathrm{Cl}_{4}\right): \delta=14.30(\mathrm{~s}, 2 \mathrm{H}, \mathrm{NH}), 7.99(\mathrm{~m}, 2 \mathrm{H}$, chinoline), 7.79-7.61 (m, $12 \mathrm{H}, 4 \mathrm{H} \mathrm{AA}^{\prime}, 8 \mathrm{H}$ chinoline), 7.34 $(\mathrm{m}, 8 \mathrm{H}, \mathrm{NPhH}), 7.19\left(\mathrm{~m}, 4 \mathrm{H}, \mathrm{XX}^{\prime}\right), 7.15(\mathrm{~m}, 8 \mathrm{H}, \mathrm{NPhH})$, $1.41(\mathrm{~s}, 18 \mathrm{H}, t$-BuH), 1.35 (s, $36 \mathrm{H}, \mathrm{NPh} t$-BuH). UV/Vis/NIR $\left(\mathrm{CH}_{2} \mathrm{Cl}_{2}\right): \lambda_{\max }(\varepsilon)=754$ (127000), $683(47000), 531$ $\left(37000 \mathrm{M}^{-1} \mathrm{~cm}^{-1}\right.$ ) nm. ESI-MS (\%): calcd. for $\mathrm{C}_{88} \mathrm{H}_{91} \mathrm{~N}_{8}$ $[\mathrm{M}+\mathrm{H}]^{+}$1259.7; found 1260.2. Elemental analysis (\%): $\mathrm{C}_{88} \mathrm{H}_{90} \mathrm{~N}_{8}$ (1259.71): calcd. C 83.90, H 7.20, N 8.90; found C 83.83, H 7.24, N 9.13.

\section{General procedure for the synthesis of $\mathrm{BF}_{2}-\mathrm{PPCy}$ dyes 4}

$\mathrm{H}-\mathrm{PPCy} 3(1 \mathrm{mmol})$ and $N, N$-diisopropylethylamine $(20 \mathrm{mmol})$ were heated to reflux in $\mathrm{CH}_{2} \mathrm{Cl}_{2} \cdot \mathrm{BF}_{3} \cdot \mathrm{Et}_{2} \mathrm{O}(40 \mathrm{mmol})$ was added, and the mixture was heated to reflux until the reaction was complete (UV/Vis/NIR). The mixture was washed with saturated, aqueous $\mathrm{NaHCO}_{3}$ solution and dried with $\mathrm{MgSO}_{4}$. After removal of the solvent, the crude product was purified by column chromatography.

\section{Compound 4a"}

Column chromatography $\left(\mathrm{CH}_{2} \mathrm{Cl}_{2}\right)$ afforded $\mathbf{4 a}$ as a violet solid in $61 \%$ yield. ${ }^{1} \mathrm{H}$ NMR $\left(400 \mathrm{MHz}, \mathrm{CDCl}_{3}\right): \delta=7.92$ $\left(\mathrm{d},{ }^{3} J=8.7 \mathrm{~Hz}, 2 \mathrm{H}, \mathrm{H}-4\right), 7.77\left(\mathrm{~m}, 4 \mathrm{H}, \mathrm{AA}^{\prime}\right), 7.68\left(\mathrm{~d},{ }^{4} J=\right.$ $1.5 \mathrm{~Hz}, 2 \mathrm{H}, \mathrm{H}-7), 7.50\left(\mathrm{dd},{ }^{3} J=8.7 \mathrm{~Hz},{ }^{4} J=1.5 \mathrm{~Hz}, 2 \mathrm{H}\right.$, $\mathrm{H}-5), 6.83(\mathrm{~m}, 4 \mathrm{H}, \mathrm{XX}), 3.42\left(\mathrm{t},{ }^{3} J=7.5 \mathrm{~Hz}, 4 \mathrm{H}, \mathrm{NCH}_{2}\right)$, $3.10\left(\mathrm{~s}, 6 \mathrm{H}, \mathrm{NCH}_{3}\right), 1.68\left(\mathrm{~m}, 4 \mathrm{H}, \mathrm{NCH}_{2} \mathrm{CH}_{2}\right), 1.40-1.28$ $\left(\mathrm{m}, 38 \mathrm{H}, 18 \mathrm{H} t-\mathrm{BuH}, 20 \mathrm{H} \mathrm{N}\left(\mathrm{CH}_{2}\right)_{2}\left(\mathrm{CH}_{2}\right)_{5}\right), 0.90\left(\mathrm{t},{ }^{3} J=6.9\right.$ $\left.\mathrm{Hz}, 6 \mathrm{H}, \mathrm{N}\left(\mathrm{CH}_{2}\right)_{7} \mathrm{CH}_{3}\right)$. UV/Vis/NIR $\left(\mathrm{CH}_{2} \mathrm{Cl}_{2}\right): \lambda_{\max }(\varepsilon)=$ 786 (67 000), $614\left(43000 \mathrm{M}^{-1} \mathrm{~cm}^{-1}\right)$ nm. ESI-MS (\%): calcd. for $\mathrm{C}_{62} \mathrm{H}_{73} \mathrm{~B}_{2} \mathrm{~F}_{4} \mathrm{~N}_{8} \mathrm{~S}_{2}[\mathrm{M}+\mathrm{H}]^{+}$1091.6; found 1091.5. Elemental analysis (\%): $\mathrm{C}_{62} \mathrm{H}_{72} \mathrm{~B}_{2} \mathrm{~F}_{4} \mathrm{~N}_{8} \mathrm{~S}_{2}$ (1091.03): calcd. C 68.25, H 6.65, N 10.27; found C 68.14, H 6.84, N 10.37.

\section{Compound 4a'}

Column chromatography $\left(\mathrm{CH}_{2} \mathrm{Cl}_{2}\right)$ afforded $\mathbf{4} \mathbf{a}^{\prime}$ as a dark blue solid in $66 \%$ yield. ${ }^{1} \mathrm{H}$ NMR $\left(400 \mathrm{MHz}, \mathrm{CDCl}_{3}\right): \delta=8.50$ $\left(\mathrm{d},{ }^{3} J=9.0 \mathrm{~Hz}, 2 \mathrm{H}, \mathrm{H}-8\right), 8.04\left(\mathrm{~d},{ }^{3} J=9.1 \mathrm{~Hz}, 2 \mathrm{H}, \mathrm{H}-4\right)$, $7.79(\mathrm{~m}, 4 \mathrm{H}, \mathrm{AA}), 7.74\left(\mathrm{dd},{ }^{3} J=9.0 \mathrm{~Hz},{ }^{4} J=1.2 \mathrm{~Hz}, 2 \mathrm{H}\right.$, $\mathrm{H}-7), 7.69\left(\mathrm{~d},{ }^{3} J=9.1 \mathrm{~Hz}, 2 \mathrm{H}, \mathrm{H}-3\right), 7.61\left(\mathrm{~d},{ }^{4} J=1.2 \mathrm{~Hz}\right.$, $2 \mathrm{H}, \mathrm{H}-5), 6.84\left(\mathrm{~m}, 4 \mathrm{H}, \mathrm{XX}^{\prime}\right), 3.43\left(\mathrm{t},{ }^{3} J=7.5 \mathrm{~Hz}, 4 \mathrm{H}\right.$, $\left.\mathrm{NCH}_{2}\right), 3.10\left(\mathrm{~s}, 6 \mathrm{H}, \mathrm{NCH}_{3}\right), 1.70\left(\mathrm{~m}, 4 \mathrm{H}, \mathrm{NCH}_{2} \mathrm{CH}_{2}\right)$, $1.40-1.28\left(\mathrm{~m}, 38 \mathrm{H}, 18 \mathrm{H} t\right.$-BuH, $\left.20 \mathrm{H} \mathrm{N}\left(\mathrm{CH}_{2}\right)_{2}\left(\mathrm{CH}_{2}\right)_{5}\right)$, $0.90\left(\mathrm{t},{ }^{3} J=6.9 \mathrm{~Hz}, 6 \mathrm{H}, \mathrm{N}\left(\mathrm{CH}_{2}\right)_{7} \mathrm{CH}_{3}\right) . \mathrm{UV} / \mathrm{Vis} / \mathrm{NIR}$ $\left(\mathrm{CH}_{2} \mathrm{Cl}_{2}\right): \lambda_{\max }(\varepsilon)=795(96000), 610\left(32000 \mathrm{M}^{-1} \mathrm{~cm}^{-1}\right) \mathrm{nm}$. ESI-MS (\%): calcd. for $\mathrm{C}_{66} \mathrm{H}_{77} \mathrm{~B}_{2} \mathrm{~F}_{4} \mathrm{~N}_{8}[\mathrm{M}+\mathrm{H}]^{+}$1079.6; found 1079.9. Elemental analysis (\%): $\quad \mathrm{C}_{66} \mathrm{H}_{76} \mathrm{~B}_{2} \mathrm{~F}_{4} \mathrm{~N}_{8}$ (1078.98): calcd. C 73.47, H 7.10, N 10.39; found C 73.10, H 7.22, N 10.53.

\section{Compound $4 b^{\prime}$}

Column chromatography (petroleum ether $/ \mathrm{CH}_{2} \mathrm{Cl}_{2}, 1: 5$ ) afforded $\mathbf{4} \mathbf{b}^{\prime}$ as a dark blue solid in $16 \%$ yield. ${ }^{1} \mathrm{H}$ NMR $\left(400 \mathrm{MHz}, \mathrm{CDCl}_{3}\right): \delta=8.51\left(\mathrm{~d},{ }^{3} J=9.3 \mathrm{~Hz}, 2 \mathrm{H}, \mathrm{H}-8\right), 8.08$ $\left(\mathrm{d},{ }^{3} J=9.0 \mathrm{~Hz}, 2 \mathrm{H}, \mathrm{H}-4\right), 7.77\left(\mathrm{dd},{ }^{3} J=9.3 \mathrm{~Hz},{ }^{4} J=2.3 \mathrm{~Hz}\right.$, $2 \mathrm{H}, \mathrm{H}-7), 7.75\left(\mathrm{~d},{ }^{3} J=9.0 \mathrm{~Hz}, 2 \mathrm{H}, \mathrm{H}-3\right), 7.69\left(\mathrm{~m}, 4 \mathrm{H}, \mathrm{AA}^{\prime}\right)$, $7.63\left(\mathrm{~d},{ }^{4} \mathrm{~J}=2.3 \mathrm{~Hz}, 2 \mathrm{H}, \mathrm{H}-5\right), 7.39(\mathrm{~m}, 4 \mathrm{H}, \mathrm{NPhH}), 7.31$ (m, $4 \mathrm{H}, \mathrm{NPhH}), 7.12(\mathrm{~m}, 2 \mathrm{H}, \mathrm{NPhH}), 7.01\left(\mathrm{~m}, 4 \mathrm{H}, \mathrm{XX}^{\prime}\right)$, $3.83\left(\mathrm{t},{ }^{3} J=7.5 \mathrm{~Hz}, 4 \mathrm{H}, \mathrm{NCH}_{2}\right.$ ), 1.77 (quint, ${ }^{3} J=7.5 \mathrm{~Hz}$, $4 \mathrm{H}, \mathrm{NCH}_{2} \mathrm{CH}_{2}$ ), 1.42 (sext, ${ }^{3} J=7.5 \mathrm{~Hz}, 4 \mathrm{H}, \mathrm{N}\left(\mathrm{CH}_{2}\right)_{2} \mathrm{CH}_{2}$ ), $1.38(\mathrm{~s}, 18 \mathrm{H}, t-\mathrm{BuH}), 0.98\left(\mathrm{t},{ }^{3} J=7.5 \mathrm{~Hz}, 6 \mathrm{H}, \mathrm{N}\left(\mathrm{CH}_{2}\right)_{3} \mathrm{CH}_{3}\right)$. UV/Vis/NIR ( $n$-butyronitrile): $\lambda_{\max }(\varepsilon)=770$ (93000), 618 $\left(24000 \mathrm{M}^{-1} \mathrm{~cm}^{-1}\right) \mathrm{nm}$. ESI-MS (\%): calcd. for $\mathrm{C}_{68} \mathrm{H}_{65} \mathrm{~B}_{2} \mathrm{~F}_{4} \mathrm{~N}_{8}$ $[\mathrm{M}+\mathrm{H}]^{+}$1091.6; found 1091.1. Elemental analysis (\%): $\mathrm{C}_{68} \mathrm{H}_{64} \mathrm{~B}_{2} \mathrm{~F}_{4} \mathrm{~N}_{8}$ (1090.90): calcd. C 73.87, H 5.91, N 10.27; found $\mathrm{C} 75.03, \mathrm{H}$ 6.18, N 10.16.

\section{Compound $4 \mathrm{c}^{\prime}$}

Column chromatography (petroleum ether $/ \mathrm{CH}_{2} \mathrm{Cl}_{2}, 1: 1$ ) afforded $\mathbf{4 c}^{\prime}$ as a turquoise solid in $19 \%$ yield. ${ }^{1} \mathrm{H}$ NMR $\left(400 \mathrm{MHz}, \mathrm{CDCl}_{3}\right): \delta=8.53\left(\mathrm{~d},{ }^{3} J=9.4 \mathrm{~Hz}, 2 \mathrm{H}, \mathrm{H}-8\right)$, $8.12\left(\mathrm{~d}, 2 \mathrm{H},{ }^{3} J=9.0 \mathrm{~Hz}, \mathrm{H}-4\right), 7.81\left(\mathrm{dd},{ }^{3} J=9.4 \mathrm{~Hz},{ }^{4} J=\right.$ $2.4 \mathrm{~Hz}, 2 \mathrm{H}, \mathrm{H}-7), 7.80\left(\mathrm{~d}, 2 \mathrm{H},{ }^{3} J=9.0 \mathrm{~Hz}, \mathrm{H}-3\right), 7.68-7.62$ (m, $\left.6 \mathrm{H}, 4 \mathrm{H} \mathrm{AA}^{\prime}, 2 \mathrm{H} \mathrm{H}-5\right), 7.33$ (m, $\left.8 \mathrm{H}, \mathrm{NPhH}\right), 7.31$ (m, 8 $\mathrm{H}, \mathrm{NPhH}), 7.17\left(\mathrm{~m}, 4 \mathrm{H}, \mathrm{XX}^{\prime}\right), 1.39(\mathrm{~s}, 18 \mathrm{H}, t-\mathrm{BuH}), 1.34$ (s, $36 \mathrm{H}, \mathrm{NPh} t-\mathrm{BuH})$. UV/Vis/NIR $\left(\mathrm{CH}_{2} \mathrm{Cl}_{2}\right): \lambda_{\max }(\varepsilon)=$ 770 (110000), $693\left(50000 \mathrm{M}^{-1} \mathrm{~cm}^{-1}\right)$ nm. ESI-MS (\%): calcd. for $\mathrm{C}_{88} \mathrm{H}_{89} \mathrm{~B}_{2} \mathrm{~F}_{4} \mathrm{~N}_{8}[\mathrm{M}+\mathrm{H}]^{+}$1355.7; found 1355.2. 
Elemental analysis (\%): $\mathrm{C}_{88} \mathrm{H}_{88} \mathrm{~B}_{2} \mathrm{~F}_{4} \mathrm{~N}_{8}$ (1355.31): calcd. C 77.99, H 6.54, N 8.27; found C 77.64, H 6.82, N 8.00.

\section{General procedure for the synthesis of $\mathrm{BPh}_{2}-\mathrm{PPCy}$ dyes 5}

$\mathrm{H}-\mathrm{PPCy} 3$ ( $1 \mathrm{mmol}$ ) and $N, N$-diisopropylethylamine (3 mmol) were heated to reflux in $\mathrm{CH}_{2} \mathrm{Cl}_{2}$. $\mathrm{BPh} 2 \mathrm{Cl}(4.6 \mathrm{mmol})$ was added, and the mixture was heated at reflux until the reaction was complete (UV/Vis/NIR). The mixture was washed with saturated, aqueous $\mathrm{NaHCO}_{3}$ solution and dried with $\mathrm{MgSO}_{4}$. After removal of the solvent, the crude product was treated with methanol in an ultrasonic bath. The solid was collected by filtration and washed with methanol. The crude product was purified by column chromatography.

\section{Compound 5a"}

Column chromatography $\left(\mathrm{CH}_{2} \mathrm{Cl}_{2} /\right.$ ethyl acetate, $\left.100: 1\right)$ afforded $\mathbf{5 a}^{\prime \prime}$ as a green solid in $62 \%$ yield. ${ }^{1} \mathrm{H}$ NMR $\left(400 \mathrm{MHz}, \mathrm{CDCl}_{3}\right): \delta=7.45(\mathrm{~d}, 2 \mathrm{H}, \mathrm{H}-7), 7.27(\mathrm{~m}, 8 \mathrm{H}$, $\mathrm{BPhH}), 7.13(\mathrm{~m}, 12 \mathrm{H}, \mathrm{BPhH}), 7.01\left(\mathrm{dd},{ }^{3} J=8.8 \mathrm{~Hz}, 2 \mathrm{H}\right.$, H-5), 6.87 (d, $\left.{ }^{3} J=8.8 \mathrm{~Hz}, 2 \mathrm{H}, \mathrm{H}-4\right), 6.36$ (m, $\left.4 \mathrm{H}, \mathrm{AA}^{\prime}\right), 6.21$ $\left(\mathrm{m}, 4 \mathrm{H}, \mathrm{XX}^{\prime}\right), 3.30\left(\mathrm{t},{ }^{3} J=7.1 \mathrm{~Hz}, 4 \mathrm{H}, \mathrm{NCH}_{2}\right), 2.94(\mathrm{~s}, 6 \mathrm{H}$, $\left.\mathrm{NCH}_{3}\right), 1.62\left(\mathrm{~m}, 4 \mathrm{H}, \mathrm{NCH}_{2} \mathrm{CH}_{2}\right), 1.36(\mathrm{~m}, 20 \mathrm{H}$, $\left.\mathrm{N}\left(\mathrm{CH}_{2}\right)_{2}\left(\mathrm{CH}_{2}\right)_{5}\right), 1.19(\mathrm{~s}, 18 \mathrm{H}, t-\mathrm{BuH}), 0.92\left(\mathrm{t},{ }^{3} J=6.9 \mathrm{~Hz}\right.$, $\left.6 \mathrm{H}, \mathrm{N}\left(\mathrm{CH}_{2}\right)_{7} \mathrm{CH}_{3}\right)$. UV/Vis/NIR $\left(\mathrm{CH}_{2} \mathrm{Cl}_{2}\right): \lambda_{\max }(\varepsilon)=794$ (145000), 715 (36000 $\left.\mathrm{M}^{-1} \mathrm{~cm}^{-1}\right) \mathrm{nm}$. ESI-MS (\%): calcd. for $\mathrm{C}_{86} \mathrm{H}_{93} \mathrm{~B}_{2} \mathrm{~N}_{8} \mathrm{~S}_{2}[\mathrm{M}+\mathrm{H}]^{+}$1323.7; found 1323.8. Elemental analysis (\%): $\mathrm{C}_{86} \mathrm{H}_{92} \mathrm{~B}_{2} \mathrm{~N}_{8} \mathrm{~S}_{2}$ (1323.46): calcd. C 78.05, H 7.01, N 8.47, S 4.85; found C 78.19, H 6.87, N 8.54, S 4.44.

\section{Compound $5 \mathbf{a}^{\prime}$}

Column chromatography $\left(\mathrm{CH}_{2} \mathrm{Cl}_{2}\right)$ afforded $\mathbf{5} \mathbf{a}^{\prime}$ as a dark green solid in $20 \%$ yield. ${ }^{1} \mathrm{H}$ NMR $\left(400 \mathrm{MHz}, \mathrm{CDCl}_{3}\right): \delta=$ 8.07 (d, 2 H, H-8), 7.74 (d, 2 H, H-4), 7.62 (d, 2 H, H-3), 7.39-7.27 (m, 10 H, 8 H BPhH, 2 H H-5), 7.15-7.05 (m, 14 H, $12 \mathrm{H} \mathrm{BPhH,} 2 \mathrm{H} \mathrm{H}-7), 6.35$ (m, $\left.4 \mathrm{H}, \mathrm{AA}^{\prime}\right), 6.06$ (m, $\left.4 \mathrm{H}, \mathrm{XX}^{\prime}\right)$, $3.40\left(\mathrm{t}, 4 \mathrm{H}, \mathrm{NCH}_{2}\right), 3.03\left(\mathrm{~s}, 6 \mathrm{H}, \mathrm{NCH}_{3}\right), 1.71(\mathrm{~m}, 4 \mathrm{H}$, $\left.\mathrm{NCH}_{2} \mathrm{CH}_{2}\right), 1.39\left(\mathrm{~m}, 20 \mathrm{H}, \mathrm{N}\left(\mathrm{CH}_{2}\right)_{2}\left(\mathrm{CH}_{2}\right)_{5}\right), 1.16(\mathrm{~s}, 18 \mathrm{H}$, $t$-BuH $), 0.92\left(\mathrm{t},{ }^{3} J=6.9 \mathrm{~Hz}, 6 \mathrm{H}, \mathrm{N}\left(\mathrm{CH}_{2}\right)_{7} \mathrm{CH}_{3}\right)$. UV/Vis/NIR $\left(\mathrm{CH}_{2} \mathrm{Cl}_{2}\right): \lambda_{\max }(\varepsilon)=829(192000), 747\left(30000 \mathrm{M}^{-1} \mathrm{~cm}^{-1}\right)$ nm. ESI-MS (\%): calcd. for $\mathrm{C}_{90} \mathrm{H}_{97} \mathrm{~B}_{2} \mathrm{~N}_{8}[\mathrm{M}+\mathrm{H}]^{+} 1311.8$; found 1312.1. Elemental analysis (\%): $\mathrm{C}_{90} \mathrm{H}_{96} \mathrm{~B}_{2} \mathrm{~N}_{8}$ (1311.40): calcd. C 82.43, H 7.38, N 8.54; found C 82.55, H 7.25, N 8.64.

\section{Compound 5 $\mathbf{b}^{\prime}$}

Column chromatography (petroleum ether $/ \mathrm{CH}_{2} \mathrm{Cl}_{2}, 1: 2$ ) afforded $\mathbf{5} \mathbf{b}^{\prime}$ as a dark green solid in $33 \%$ yield. ${ }^{1} \mathrm{H}$ NMR $\left(400 \mathrm{MHz}, \mathrm{C}_{2} \mathrm{D}_{2} \mathrm{Cl}_{4}\right): \delta=8.14\left(\mathrm{~d},{ }^{3} J=9.2 \mathrm{~Hz}, 2 \mathrm{H}, \mathrm{H}-8\right), 7.79$ (d, $\left.{ }^{3} J=9.2 \mathrm{~Hz}, 2 \mathrm{H}, \mathrm{H}-4\right), 7.60\left(\mathrm{~d},{ }^{3} J=9.2 \mathrm{~Hz}, 2 \mathrm{H}, \mathrm{H}-3\right)$, 7.35 (m, 8 H, BPhH), 7.32-7.25 (m, $6 \mathrm{H}, 4 \mathrm{H} \mathrm{NPhH,} 2 \mathrm{H} \mathrm{H}-5)$, 7.18-7.12 (m, $6 \mathrm{H}, 4 \mathrm{H} \mathrm{NPhH,} 2 \mathrm{H} \mathrm{H}-7), 7.05$ (m, $12 \mathrm{H}$, $\mathrm{BPhH}), 6.90(\mathrm{~m}, 2 \mathrm{H}, \mathrm{NPhH}), 6.61\left(\mathrm{~m}, 4 \mathrm{H}, \mathrm{AA}^{\prime}\right), 6.00(\mathrm{~m}$, $4 \mathrm{H}, \mathrm{XX}^{\prime}$ ), $3.72\left(\mathrm{t},{ }^{3} J=7.2 \mathrm{~Hz}, 4 \mathrm{H}, \mathrm{NCH}_{2}\right.$ ), 1.74 (quint, ${ }^{3} J=$ $\left.7.2 \mathrm{~Hz}, 4 \mathrm{H}, \mathrm{NCH}_{2} \mathrm{CH}_{2}\right), 1.52(\mathrm{~s}, 18 \mathrm{H}, t-\mathrm{BuH}) 1.44\left(\mathrm{sext},{ }^{3} J=\right.$ $\left.7.2 \mathrm{~Hz}, 4 \mathrm{H}, \mathrm{N}\left(\mathrm{CH}_{2}\right)_{2} \mathrm{CH}_{2}\right), 1.01\left(\mathrm{t},{ }^{3} \mathrm{~J}=7.2 \mathrm{~Hz}, 6 \mathrm{H}\right.$, $\left.\mathrm{N}\left(\mathrm{CH}_{2}\right)_{3} \mathrm{CH}_{3}\right)$. UV/Vis/NIR $\left(\mathrm{CH}_{2} \mathrm{Cl}_{2}\right): \lambda_{\max }(\varepsilon)=825$ (209000), 741 (31000 $\left.\mathrm{M}^{-1} \mathrm{~cm}^{-1}\right)$ nm. ESI-MS (\%): calcd. for $\mathrm{C}_{92} \mathrm{H}_{85} \mathrm{~B}_{2} \mathrm{~N}_{8}[\mathrm{M}+\mathrm{H}]^{+}$1323.7; found 1323.8. Elemental analysis (\%): $\mathrm{C}_{92} \mathrm{H}_{84} \mathrm{~B}_{2} \mathrm{~N}_{8}$ (1323.33): calcd. C 83.50, H 6.40, N 8.47; found C 83.73, H 6.60, N 8.30.

\section{Compound 5 $\mathbf{c}^{\prime}$}

Column chromatography (petroleum ether $/ \mathrm{CH}_{2} \mathrm{Cl}_{2}, 1: 1$ ) afforded $\mathbf{5} \mathbf{c}^{\prime}$ as a green solid in $48 \%$ yield. ${ }^{1} \mathrm{H}$ NMR $\left(400 \mathrm{MHz}, \mathrm{CDCl}_{3}\right): \delta=8.16\left(\mathrm{~d},{ }^{3} J=9.5 \mathrm{~Hz}, 2 \mathrm{H}, \mathrm{H}-8\right)$, $7.85\left(\mathrm{~d},{ }^{3} J=9.0 \mathrm{~Hz}, 2 \mathrm{H}, \mathrm{H}-4\right), 7.75\left(\mathrm{~d},{ }^{3} \mathrm{~J}=9.0 \mathrm{~Hz}, 2 \mathrm{H}\right.$, H-3), 7.42 (m, $8 \mathrm{H}, \mathrm{BPhH}), 7.38-7.32$ (m, $10 \mathrm{H}, 8 \mathrm{H} \mathrm{NPhH,}$ $2 \mathrm{H} \mathrm{H}-5), 7.23$ (m, $8 \mathrm{H}, \mathrm{NPhH}), 7.19\left(\mathrm{dd},{ }^{3} \mathrm{~J}=9.5 \mathrm{~Hz},{ }^{4} \mathrm{~J}=\right.$ $2.5 \mathrm{~Hz}, 2 \mathrm{H}, \mathrm{H}-7), 7.14-7.03(\mathrm{~m}, 12 \mathrm{H}, \mathrm{BPhH}), 6.77(\mathrm{~m}, 4 \mathrm{H}$, $\left.\mathrm{AA}^{\prime}\right), 6.08\left(\mathrm{~m}, 4 \mathrm{H}, \mathrm{XX}^{\prime}\right), 1.37$ (s, $\left.36 \mathrm{H}, \mathrm{NPh} t-\mathrm{BuH}\right), 1.19$ (s, $18 \mathrm{H}, t$-BuH $) . \mathrm{UV} / \mathrm{Vis} / \mathrm{NIR}\left(\mathrm{CH}_{2} \mathrm{Cl}_{2}\right): \lambda_{\max }(\varepsilon)=826$ (206000), $742\left(33000 \mathrm{M}^{-1} \mathrm{~cm}^{-1}\right) \mathrm{nm}$. ESI-MS (\%): calcd. for $\mathrm{C}_{112} \mathrm{H}_{109} \mathrm{~B}_{2} \mathrm{~N}_{8}[\mathrm{M}+\mathrm{H}]^{+}$1587.9; found 1588.5. Elemental analysis (\%): $\mathrm{C}_{112} \mathrm{H}_{108} \mathrm{~B}_{2} \mathrm{~N}_{8}$ (1587.73): calcd. C 84.72, H 6.86, N 7.06; found C 84.40, H 7.57, N 6.72 .

\section{Acknowledgements}

We gratefully acknowledge financial support from the DFG through SFB767.

\section{Notes and references}

1 E. M. Sevick-Muraca, J. P. Houston and M. Gurfinkel, Curr. Opin. Chem. Biol., 2002, 6, 642-650.

2 S. A. Hilderbrand and R. Weissleder, Curr. Opin. Chem. Biol., 2010, 14, 71-79.

3 G. Qian and Z. Y. Wang, Chem.-Asian J., 2010, 5, 1006-1029.

4 J. Fabian, H. Nakazumi and M. Matsuoka, Chem. Rev., 1992, 92, $1197-1226$.

5 C. J. Jiao and J. S. Wu, Curr. Org. Chem., 2010, 14, 2145-2168.

6 A. B. Descalzo, H.-J. Xu, Z. Shen and K. Rurack, Ann. N. Y. Acad. Sci., 2008, 1130, 164-171.

7 J. O. Escobedo, O. Rusin, S. Lim and R. M. Strongin, Curr. Opin. Chem. Biol., 2010, 14, 64-70.

8 Y. Avlasevich and K. Müllen, Chem. Commun., 2006, 4440-4442.

9 F. Holtrup, G. Müller, H. Quante, S. Defeyter, F. DeSchryver and K. Müllen, Chem.-Eur. J., 1997, 3, 219-225.

10 C. Kohl, S. Becker and K. Müllen, Chem. Commun., 2002, 2778-2779.

11 J. J. Gassensmith, J. M. Baumes and B. D. Smith, Chem. Commun., 2009, 6329-6338.

12 G. M. Fischer, A. P. Ehlers, A. Zumbusch and E. Daltrozzo, Angew. Chem., Int. Ed., 2007, 46, 3750-3753.

13 G. M. Fischer, M. Isomäki-Krondahl, I. Göttker-Schnetmann, E. Daltrozzo and A. Zumbusch, Chem.-Eur. J., 2009, 15, $4857-4864$.

14 G. M. Fischer, E. Daltrozzo and A. Zumbusch, Angew. Chem., Int. Ed., 2011, 50, 1406-1409.

15 G. M. Fischer, M. K. Klein, A. Zumbusch and E. Daltrozzo, Eur. J. Org. Chem., 2011, 3421-3429.

16 G. M. Fischer, C. Jüngst, M. Isomäki-Krondahl, D. Gauss, H. M. Möller, E. Daltrozzo and A. Zumbusch, Chem. Commun. (Cambridge, U. K.), 2010, 46, 5289-5291.

17 R. Ziessel, G. Ulrich, A. Harriman, M. A. H. Alamiry, B. Stewart and P. Retailleau, Chem.-Eur. J., 2009, 15, 1359-1369.

18 T. Yamagata, J. Kuwabara and T. Kanbara, Tetrahedron Lett., 2010, 51, 1596-1599.

19 M. Kaplanova and K. Cermak, J. Photochem., 1981, 15, 313-319.

20 S. Strickler and R. Berg, J. Chem. Phys., 1962, 37, 814-822.

21 F. Menges, Spekwin32-free optical spectroscopy software, 1.71 .5 edn, 2010.

22 M. Klessinger and J. Michl, Exited states and photochemistry of organic molecules, $\mathrm{VCH}$, Weinheim, 1995. 